\title{
Extraordinary times call for extraordinary measures: the use of music to communicate public health recommendations against the spread of COVID-19
}

\author{
Elise Cournoyer Lemaire ${ }^{1}$ (D) \\ Received: 1 June 2020 / Accepted: 25 June 2020 / Published online: 22 July 2020 \\ (C) The Canadian Public Health Association 2020
}

\begin{abstract}
To promote the population's adherence to COVID-19 public health preventive measures, the Quebec (Canada) government solicited the assistance of local music artists. This commentary aims to demonstrate how music has been utilized to communicate the public health recommendations relative to the COVID-19 pandemic and to discuss the relevance of using music in this context, as supported by research. More specifically, music is discussed in terms of its powerful capacity to reach out to a large population pool; to capture the population's attention quickly and massively in spite of age, language, or cultural barriers; to effectively communicate messages; and to affect individuals' behaviours. In this regard, the current COVID-19 pandemic demonstrates how music can be utilized as a communication tool and offers an interesting perspective for the consideration of music in future public health research.
\end{abstract}

\section{Résumé}

Dans le but de promouvoir l'adhésion de la population aux mesures préventives de santé publique émises en réponse à la COVID-19, le gouvernement du Québec (Canada) a solicité l'appui d'artistes musicaux locaux. Ce commentaire vise à démontrer la façon dont la musique a été utilisée pour communiquer les recommandations de santé publique en lien avec la pandémie de la COVID-19 et à explorer la pertinence d'utiliser la musique dans ce contexte, en s'appuyant sur la recherche. Plus spécifiquement, la musique est abordée en termes de son importante capacité à rejoindre un large bassin de la population, de capter l'attention de la population rapidement et massivement en dépit des barrières pouvant être reliées à l'âge, au niveau de langage ou à la culture des personnes, à communiquer des messages de façon efficace, et à influer sur le comportement des individus. Dans cette perspective, la présente pandémie de la COVID-19 démontre le potentiel de la musique comme outil de communication et offre des pistes intéressantes quant à la considération de la musique dans les recherches futures en santé publique.

Keywords Public health $\cdot$ COVID-19 $\cdot$ Communication $\cdot$ Music

Mots-clés Santé publique $\cdot$ COVID-19 $\cdot$ Communication $\cdot$ Musique

\section{Context}

Since the beginning of the COVID-19 pandemic, enormous efforts have been invested around the world to prevent the

Elise Cournoyer Lemaire

elise.cournoyer.lemaire@usherbrooke.ca

1 Faculty of Medicine and Health Sciences, Department of Community Health Sciences, University of Sherbrooke, Longueuil, QC, Canada spread of the disease. Early on in Quebec (Canada), the government developed public health recommendations that have been reiterated daily ever since: wash hands frequently, avoid gatherings and non-essential travel, and maintain physical distancing. Despite these efforts, the country faced worrisome challenges when a portion of the citizens did not follow these recommendations, perhaps because they deliberately ignored them or because they were simply not aware of them. In an attempt to prompt the population to adhere to the public health recommendations to prevent the spread of COVID-19, it appeared instinctive for the government to request assistance 
from local music artists. As a response, we observed an upsurge of musical pieces of all genres in which lyrics provide information relative to the COVID-19 symptoms, public health recommendations, and the importance of following them. Numerous musical pieces communicating the COVID-19 preventive measures keep emerging and appear daily in the news, in press briefings, and in online media platforms (e.g., YouTube). The million views they receive demonstrate the public's interest towards this exceptional measure. Yet, beyond its entertaining property, research shows that there are numerous reasons to turn to music to promote the population's adherence to public health measures. This commentary aims to briefly explain how music may facilitate individuals' adherence to such measures through its well-established capacity to reach out and capture people's attention, to communicate effectively, and to affect individuals' behaviours.

\section{Reaching out to the population}

Given that the entire population is concerned by this global crisis, it is essential that the information relative to COVID-19 be broadly disseminated so as to reach as many people as possible. Diffusion through television channels is one way to achieve this aim, yet the use of music appears to be a relevant complementary means. Indeed, research has shown that music more effectively attracts individuals' attention and is more readily accessible to individuals of any age, culture, and mental or language levels compared with speech alone (Egermann et al. 2015). Additionally, a large proportion of the population is keen about listening to music; it is among the most common activities in which individuals engage, especially youths and young adults (Greasley and Lamont 2009). Thus, music has the potential to reach populations not reached through traditional media (e.g., television, radio news), hence increasing the capacity to inform a greater proportion of the population about the public health measures implemented to slow the propagation of COVID-19. Furthermore, the musical structure (e.g., rhythm, melody) is particularly powerful to capture individuals' attention which in turn may enhance one's memory for the communicated message (Haugtvedt et al. 2018). This initial step sets the stage for the effective communication of public health recommendations.

\section{Communicating effectively}

Music also encompasses multiple properties that make it a promising tool to enhance the communication process of the public health messages. First, music is universally recognized as a communicative medium that transcends cultural and language barriers (Mehr et al. 2018). Through its capacity to connect with people beyond such barriers, music also has an extraordinary capacity to generate new or stronger social bonds between individuals and communities (Tarr et al. 2014), which in turn strengthens global solidarity in adhering to the communicated information and then pulls communities towards the achievement of common goals (Fetchenhauer et al. 2006). Furthermore, the regular exposure to music lyrics that address a particular theme tends to increase the likelihood that individuals will adopt the communicated information. Hence, frequent exposures to music conveying COVID-19 preventive measures could help individuals, and especially younger populations, to adhere to such measures and adapt their behaviours consequently, as has been observed in other helping behaviours (Greitemeyer 2009). Furthermore, individuals' adherence to musically transmitted information increases when it is performed by an artist they admire or with whom they identify, or through a personally significant song (Fraser and Brown 2002; Petering et al. 2017; Allan 2006), supporting the importance of soliciting the contribution of multiple known artists. The elevated response rate from numerous music artists of different genres thus represents a major strength in communicating information relative to the current pandemic. Additionally, research shows that popular music and music interpreted by known artists are not only good at capturing attention but also at facilitating the integration of information, their memory and their recall, factors that are essential to an effective communication (Allan 2006).

\section{Music modulates behaviours}

Ultimately, communicating through music could contribute to promote the adoption of appropriate behaviours in the context of the current COVID-19 pandemic. Indeed, research shows that music affects individuals' behaviours, mostly through its emotional impact (Juslin and Sloboda 2010). In the case of the musical pieces diffusing the public health recommendations relative to COVID-19, we observe that the vast majority of them use parameters known to induce positive emotions in the listeners (e.g., major mode, fast tempo; Gomez et al. 2007). Consequently, the message becomes associated with positive emotions and may encourage the population to accept, adhere to, and perform the recommended behaviours (Juslin and Sloboda 2010). In other words, music carries an emotional value that may modulate the listeners' behaviours through the association between the recommended behavioural measures and positive emotions.

Music also affects behaviours through the frequency with which individuals are exposed to its messages. Indeed, the more that people are exposed to the music, the more they tend to integrate the conveyed information and perform associated behaviours (Margulis 2013; Swartbooi et al. 2016). Moreover, 
the integration of those messages may lead to the development of an intrinsic motivation to apply the recommended public health measures, which is a stronger indicator of adherence compared with extrinsic motivational sources (e.g., law enforcement; Seifert et al. 2012).

\section{Conclusion}

Briefly, music constitutes a resource that allows for rapid and massive transmission of information to a variety of audiences. As COVID-19-related music keeps emerging and attracting the attention of millions of individuals in record time, the current exceptional context shows that it is a promising means to communicate public health information, in addition to being based on individuals' interests. Indeed, the use of music encompasses the essentials of an effective communication strategy. According to science, the thoughtful manipulation of structural and emotional musical parameters makes music a powerful and innovative communication tool that can effectively capture attention, connect and communicate with the population about the public health recommendations relative to the crisis in question, and increase the likelihood that these measures will be viewed positively and that individuals' behaviours will be adapted accordingly.

However, while research supports music's capacity to modulate individuals' behaviours, its impact on populations' adherence with public health recommendations more specifically is unknown. Nevertheless, the actual COVID-19 pandemic context demonstrates the relevance of considering music as a potential communication tool in the global domain of public health in future research.

\section{Compliance with ethical standards}

Conflict of interest The author declares that there is no conflict of interest.

\section{References}

Allan, D. (2006). Effects of popular music in advertising on attention and memory. Journal of Advertising Research, 434-444.
Egermann, H., Fernando, N., Chuen, L., \& McAdams, S. (2015). Music induces universal emotion-related psychophysiological responses: comparing Canadian listeners to Congolese Pygmies. Frontiers in Psychology, 5(1341), 1-9.

Fetchenhauer, D., Flache, A., Buunk, B., \& Lindenberg, S. (Eds.). (2006). Solidarity and prosocial behavior: an integration of sociological and psychological perspectives. Boston (US): Springer.

Fraser, B. P., \& Brown, W. J. (2002). Media, celebrities, and social influence: identification with Elvis Presley. Mass Communication and Society, 5(2), 183-206.

Gomez, P., Danuser, B., \& Phelps, E. A. (2007). Relationships between musical structure and psychophysiological measures of emotion. Emotion, 7(2), 377-387.

Greasley, A. E., \& Lamont, A. (2009). Exploring engagement with music in everyday life using experience sampling methodology. Musicae Scientiae, 15(1), 45-71.

Greitemeyer, T. (2009). Effects of songs with prosocial lyrics on prosocial behavior: further evidence and a mediating mechanism. Personality and Social Psychology Bulletin, 35(11), 1500-1511.

Haugtvedt, C. P., Herr, P. M., \& Kardes, F. R. (2018). Handbook of consumer psychology. Marketing and Consumer Psychology Series. Routledge (ed.). 1296 p.

Juslin, P. N., \& Sloboda, J. A. (Eds.). (2010). Handbook of music and emotion: theory, research, applications. Oxford (UK): Oxford University Press.

Margulis, E. H. (2013). Repetition and emotive communication in music versus speech. Frontiers in Psychology, 4(167).

Mehr, S. A., Singh, M., York, H., Glowacki, L., \& Krasnow, M. M. (2018). Form and function in human song. Current Biology, 28, 356-368.

Petering, R., Rhoades, H., Winetrobe, H., Dent, D., \& Rice, E. (2017). Violence, trauma, mental health, and substance use among homeless youth Juggalos. Child Psychiatry and Human Development, 48, 642-650.

Seifert, C. M., Chapman, L. S., Hart, J. K., \& Perez, P. (2012). Enhancing intrinsic motivation in health promotion and wellness. American Journal of Health Promotion, 26(3), 1-10.

Swartbooi, C., Sabahi, S., Isobell, D., Khan, G., Wagenaar, C., Makonyonga, F., et al. (2016). Adolescents' perceptions of health and well-being: influences of urban contemporary music. Journal of Psychology in Africa, 26(4), 379-383.

Tarr, B., Launay, J., \& Dunbar, R. I. M. (2014). Music and social bonding: "self-other" merging and neurohormonal mechanisms. Frontiers in Psychology, 5(1096), 1-10.

Publisher's note Springer Nature remains neutral with regard to jurisdictional claims in published maps and institutional affiliations. 